Purdue University

Purdue e-Pubs

2000

\title{
Heat Transfer from a Finned Surface in Ducted Air Jet Suction and Impingement
}

\author{
L. A. Brignoni
}

S V. Garimella

Purdue University, sureshg@purdue.edu

Follow this and additional works at: http://docs.lib.purdue.edu/coolingpubs

Brignoni, L. A. and Garimella, S V., "Heat Transfer from a Finned Surface in Ducted Air Jet Suction and Impingement" (2000). CTRC Research Publications. Paper 300.

http://docs.lib.purdue.edu/coolingpubs/300

This document has been made available through Purdue e-Pubs, a service of the Purdue University Libraries. Please contact epubs@purdue.edu for additional information. 


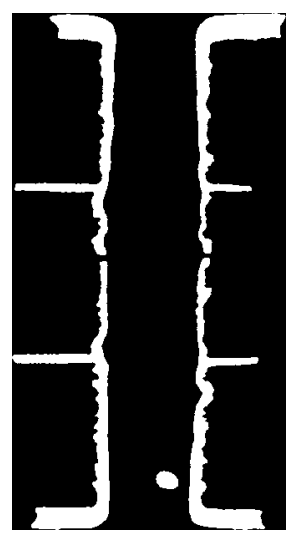

Fig. 4 Cross-sections of plated-through hole

\section{Heat Transfer From a Finned Surface in Ducted Air Jet Suction and Impingement}

\author{
Luis A. Brignoni \\ Department of Mechanical Engineering, University of \\ Wisconsin-Milwaukee, P.O. Box 784, \\ Milwaukee, WI 53201

\section{Suresh V. Garimella} \\ Associate Professor, School of Mechanical Engineering, \\ Purdue University, West Lafayette, IN 47907-1288 \\ Mem ASME \\ e-mail: sureshg@ecn.purdue.edu
}

Comparing the assumptions of Models \#1 and \#3, we can see that the level of accounting for the three-dimensional nature of PTH is identical. The material properties in both models are assumed to be temperature-dependent and dependent on the stress levels. There are some insignificant differences. For example, the Model \#3 accounts for a variable barrel thickness, whereas the Model \#1 assumes that the barrel thickness is constant for the entire PTH barrel. Without any complications, both models can be developed in an identical manner. This is true as far as both models are axisymmetric. Of course, the FE method has the advantage to consider the general 3D elements what in the closed-form solution would be very cumbersome. This fact, however, does not relate to the comparison of Models \#1 and \#3.

Comparing Figs. 1-3 with cross-sections of actual PTH's (Fig. 4), we can see that application of FE method does not bring the model geometry closer to the real structure. The material properties used in FE model are those typically used in the microelectronic industry. For example, the barrel-copper properties are taken from the tests of board layer plating-though there exists evidence that these coppers may have significantly different properties, as well as the properties of plated copper may vary in the range of \pm 50 percent (Safranek [5]).

In addition to this indefiniteness in the geometry and material properties, it is known for such FE multimaterial models that there is a high mesh sensitivity of the numerical results. Therefore, we cannot consider the FE model's quantitative results to be highly accurate. High dependence of the failure indicators (maximum equivalent plastic strains) on many geometrical and material parameters of the structure makes it impossible to generalize conclusions derived from one pilot set of results to all PTH structures.

These limitations of the FE method must be taken into consideration when a tool for the stress analysis of a microelectronic structure is chosen. Exchange of opinions on these issues would be very useful for our engineering community.

\section{References}

[1] Orringer, O. and Tong, P., 1984, "Uses and abuses of the finite element method," Proceedings of SPIE, the International Society for Optical Engineering, Vol. 450, Bellingham, Washington, DC, pp. 2-33.

[2] Subbarayan, G., Ramakrishna, K., and Sammakia, B. G., 1997, “The Impact of Interfacial Adhesion on PTH and Via Stress State," ASME J. Electron. Packag., 119, pp. 260-267.

[3] Engelmaier, W., 1988, "Plated Through Hole Failures in Thermal Cycling: Analytical Considerations," Technical Report IPC-TR-579, Lincolnwood, IL.

[4] Mirman, B., 1988, "Mathematical Model of a Plated-Through Hole under a Load Induced by Thermal Mismatch,' IEEE Trans., CHMT, 11, No. 4, pp. 506-511.

[5] Safranek, W. H., 1986, "The Properties of Electrodeposited Metals and Alloys," American Electroplaters and Surface Finishers Society, Handbook.
Experimental measurements were obtained to characterize the thermal performance of ducted air suction in conjunction with a pin-fin heat sink. Four single nozzles of different diameters and two multiple-nozzle arrays were studied at a fixed nozzle-to-target distance, for different turbulent Reynolds numbers $(5000 \leqslant R e$ $\leqslant 20,000)$. Variations of nozzle-to-target distance, i.e., open area, in ducted suction were found to have a strong effect on heat transfer especially with the larger diameter single nozzle and both multiple-nozzle arrays. Enhancement factors were computed with the heat sink in suction flow, relative to a bare surface, and were in the range of 8.3 to 17.7, with the largest value being obtained for the nine-nozzle array. Results from the present study on air jet suction are compared with previous experiments with air jet impingement on the pin-fin heat sink. Average heat transfer coefficients and thermal resistance values are reported for the heat sink as a function of Reynolds number, air flow rate, and pumping power. [S1043-7398(00)00903-8]

Keywords: Electronics Cooling, Jet Impingement, Air Suction, Pull and Push Modes, Air Jets, Confined Jets, Heat Sinks, Pin Fins

\section{Introduction}

Air jet impingement has proven to be among the more desirable cooling techniques for electronic equipment, and is very effective when used in conjunction with extended surfaces (Choi and Kim [1], Copeland [2], Bartilson [3], Brignoni and Garimella [4], and El-Sheikh and Garimella [5]). It offers a reliable and simple method for managing heat dissipation in increasingly miniaturized electronic components. In contrast to impingement, the application of concern in the present study is the cooling of electronic components by confined suction of air. Air suction (in a pullmode, as opposed to the push-mode in impingement) is desirable in practical applications of jet impingement since it circumvents problems concerning exhaust of the heated spent air. In impingement on multiple chips on a circuit board, heated exhausts from neighboring chips can have a detrimental effect on the cooling rates achieved. In suction (pull-mode) on the other hand, fresh inlet air is drawn over the chips, and the heated spent air is channeled away from the chips. The suction arrangement is also beneficial since it allows the lowest-velocity air to have the greatest

Contributed by the Electrical and Electronic Packaging Division of THE AMERICAN SOCIETY OF MECHANICAL ENGINEERS. Manuscript received by the EEPD February 1999; revised manuscript received December 1999. Associate Technical Editor: R. Wirtz. 
surface-to-coolant temperature difference; as the coolant picks up heat from the target, it also speeds up, thus compensating for its expected loss in heat-removal capability.

The present study seeks to understand the effects of the governing variables (nozzle diameter, flow rate $\dot{V}$, nozzle-to-target spacing and number of nozzles) in confined air suction from enhanced surfaces. Comparisons with a previous study on confined air jet impingement (Brignoni and Garimella [4]) are made to explore the heat transfer capabilities of three flow schemes: baresurface air suction, enhanced-surface air suction and enhancedsurface air impingement.

\section{Experimental Setup and Procedures}

The experiments were conducted in the same facility as used in previous studies (Brignoni and Garimella [4]; Schroeder and Garimella [6]) but with the air flow direction reversed; details of the experimental facility and procedures are available in these references. A plastic duct was glued to each nozzle plate to force the air flow into the lower portion of the pin-fin heat sink and reduce bypass between the nozzle plate and the fin tips (Fig. 1). The duct has an inside width $\left(W_{d}\right)$ of $19.5 \mathrm{~mm}$, length $\left(L_{d}\right)$ of $16.8 \mathrm{~mm}$, and wall thickness $(t)$ of $6 \mathrm{~mm}$. The nozzle-to-target distance $H$ is set using high-precision gage blocks. The duct clearance $\left(C_{d}\right)$ at the air inlet was fixed at $2.7 \mathrm{~mm}$ for experiments with air suction on both bare and enhanced surfaces. The pressure drop $(\Delta P)$ is measured with a manometer using a pressure tap located in the wall of the plenum. The ambient temperature $\left(T_{\infty}\right)$ is measured using a 20 gauge $T$-type thermocouple just beyond the confinement region.

Four different orifice diameters were studied for the singlenozzle experiments: $d=1.59,3.18,6.35$, and $12.7 \mathrm{~mm}$; two configurations were studied for multiple-nozzle experiments: an array of four $3.18 \mathrm{~mm}$ diameter nozzles $(4 \times 3.18)$, and another with

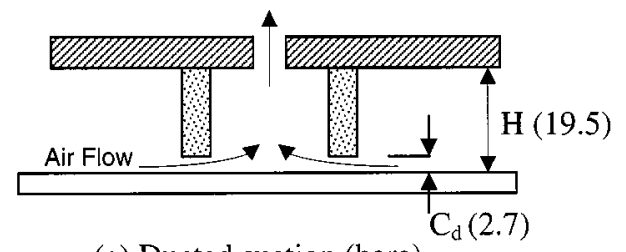

(a) Ducted suction (bare)

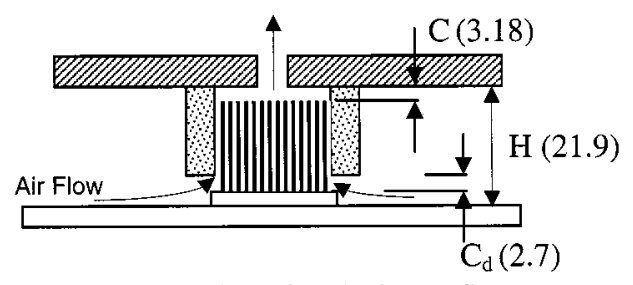

(b) Ducted suction (enhanced)

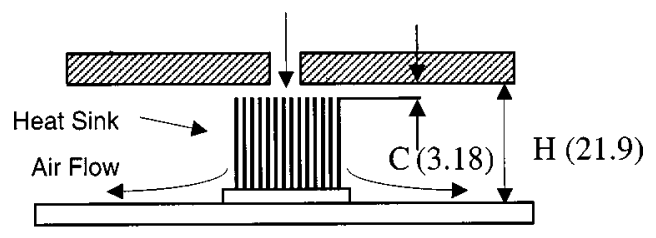

(c) Impingement (enhanced)

Fig. 1 Schematic diagrams for: (a) bare surface with ducted suction; (b) enhanced surface with ducted suction; and (c) enhanced surface with jet impingement. All dimensions are in mm. nine $1.59 \mathrm{~mm}$ diameter nozzles $(9 \times 1.59)$. The spacing between the multiple nozzles was fixed at four nozzle diameters. All orifices have an aspect ratio $l / d$ of 1 .

The $20 \times 20 \mathrm{~mm}$ heat source, which is flush-mounted to the target plate and exposed to air flow, has a heated copper block construction as described in Brignoni and Garimella [4]. The surface temperature $\left(T_{s}\right)$ is measured with five 36 gauge $T$-type thermocouples inserted just underneath the surface. The input power $\left(Q_{\text {gen }}\right)$ was provided by imbedded cartridge heaters.

A heat sink (custom-manufactured by PinFin, Inc.) is held on to the heat source by cantilever clamps, which exert a repeatable, constant force. The heat sink has a $20 \times 20 \mathrm{~mm}$ copper base, which is $2.4 \mathrm{~mm}$ thick. The copper pin fins are of circular cross-section with a $0.9 \mathrm{~mm}$ diameter, and are $16.4 \mathrm{~mm}$ high. The heat sink has a total of 72 pins with a pitch of $1.59 \mathrm{~mm}$. The interface material clamped between the heat sink and the heated surface is T-pli 210 (Thermagon, Inc.).

The heat losses were determined experimentally in a manner similar to that of Obot and Trabold [7]; details are provided in Brignoni and Garimella [4]. A linear relationship was experimentally found between the power losses $\left(Q_{\text {loss }}\right)$ and the surface-toambient temperature difference:

$$
Q_{\text {loss }}=0.096 \cdot\left(T_{s}-T_{\infty}\right)
$$

The average heat transfer coefficients in the bare and enhancedsurface experiments are obtained as:

$$
\begin{gathered}
\bar{h}_{\text {bare }}=\frac{Q_{\text {out }}}{A_{h} \cdot\left(T_{s}-T_{\infty}\right)} \\
\bar{h}_{\text {enhanced }}=\frac{Q_{\text {out }}}{A_{h} \cdot\left(T_{\text {base }}-T_{\infty}\right)}
\end{gathered}
$$

in which $T_{\text {base }}$ is the temperature within the base of the heat sink, and $Q_{\text {out }}$ is the difference between $Q_{\text {gen }}$ and $Q_{\text {loss }}$. In both cases, the heat transfer coefficient is based on the bare surface area, $A_{h}$, of $20 \times 20 \mathrm{~mm}$.

The uncertainty in measured heat transfer coefficient at 95 percent confidence for the enhanced-surface experiments with air jet suction and impingement was estimated to range from 2.1 to 5.3 percent and 2.9 to 5.8 percent, respectively. The greatest contribution ( 73 percent) to the estimated uncertainties in the heat transfer coefficient resulted from uncertainties in the temperature measurement.

The aims of the experiments are to characterize air jet suction heat transfer from a pin-fin heat sink and to obtain enhancement factors relative to bare-surface results under comparable conditions. The enhanced-surface results obtained from experiments in suction are then also compared to those from a previous study on jet impingement (Brignoni and Garimella [4]). Experiments with ducted air suction were performed for Reynolds numbers of 5000 to $20,000(15,000$ for the single $1.59 \mathrm{~mm}$ and $9 \times 1.59 \mathrm{~mm}$ array $)$ with the nozzle-to-target distance fixed at $H=19.5 \mathrm{~mm}$ for experiments on the bare surface (Fig. 1(a)). For suction from the enhanced-surface, $H$ was set at $21.9 \mathrm{~mm}$ to account for the thickness of the heat sink base; thus, $C_{d}=2.7 \mathrm{~mm}$, and is the same for both enhanced and unenhanced experiments as demonstrated in Figs. 1 $(a)$ and $1(b)$. The enhancement in heat transfer obtained as a result of introducing the heat sink is reported in terms of an enhancement factor $\varepsilon$. The performance of the suction arrangement is also contrasted with jet impingement at the same nozzleto-target spacing (Figs. 1(b) and 1(c)).

\section{Results and Discussion}

As a baseline, the heat transfer in suction without a duct in place is first examined. The effect of changing the nozzle-to-target spacing on the heat transfer coefficient in nonducted suction $\left(\bar{h}_{\text {bare }}\right)$ is shown in Fig. 2 for all nozzle diameters at $\mathrm{Re}=10,000$ (as a function of normalized spacing $H / d$ ). The strong dependence of heat transfer on $H / d$ is evident, especially for the multiple 


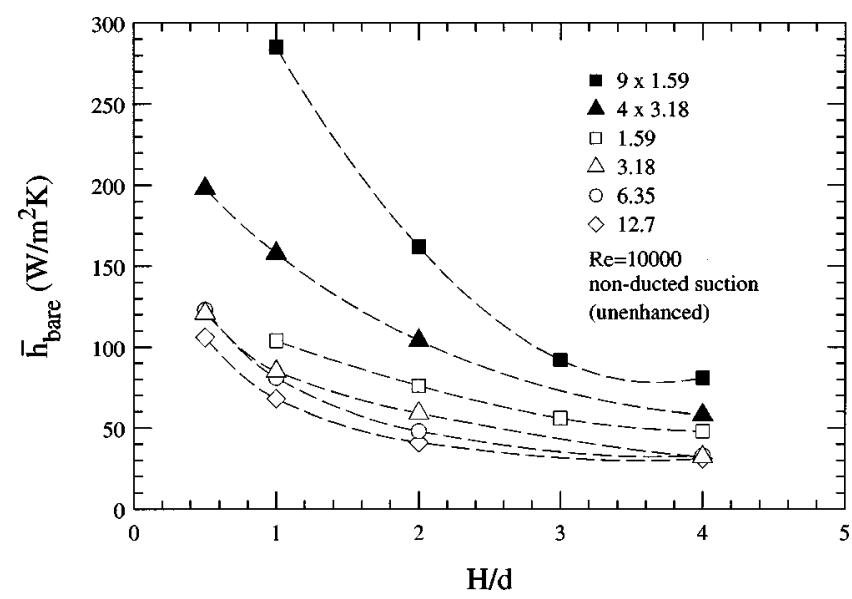

Fig. 2 Variation of bare surface heat transfer coefficient for different values of nozzle-to-target spacing at $R e=10,000$ (nonducted suction)

nozzle arrays. For instance, with the $9 \times 1.59 \mathrm{~mm}$ array, increasing $H / d$ from 1 to 2 causes a reduction in $\bar{h}_{\text {bare }}$ of 43 percent. Similarly, for the $4 \times 3.18 \mathrm{~mm}$ array, an increase in $H / d$ from 0.5 to 1 results in a reduction in $\bar{h}_{\text {bare }}$ of 20 percent. The dependence of $\bar{h}_{\text {bare }}$ on nozzle-to-target spacing is most significant at the smaller spacings, and appears to level off for $H / d \geqslant 4$. Clearly, as $H / d$ increases, less and less of the suction stream is in effective contact with the heat source. The duct attached to the nozzle plate (Figs. $1(a)$ and $1(b))$ is designed to redress the situation by forcing the incoming air flow to pass closer to the heat source prior to suction into the nozzle, and is used in all subsequent experiments.

Figure 3(a) shows the bare-surface (unenhanced) heat transfer coefficients at different Reynolds numbers in ducted suction. The average heat transfer coefficient $\bar{h}_{\text {bare }}$ increases substantially as Reynolds number is increased. The behavior of the single 1.59 $\mathrm{mm}$ diameter nozzle is the exception, and may be attributed to the very low volume flow rates and associated low velocities in the duct for this nozzle.

The enhanced heat transfer rates obtained in ducted suction (Fig. 1(b)) upon the introduction of the heat sink were measured for the same range of Reynolds numbers as for the bare-surface above, and are shown in Fig. 3(b). Due to pressure drop limitations the single $1.59 \mathrm{~mm}$ diameter nozzle was tested at only $\mathrm{Re}$ $=5000$ and 10,000. Among all the bare-surface (unenhanced) experiments (Fig. 3(a)) it was found that the maximum value for $\bar{h}_{\text {bare }}$ was $173 \mathrm{~W} / \mathrm{m}^{2} \mathrm{~K}$ with the single $12.7 \mathrm{~mm}$ diameter nozzle at $\operatorname{Re}=20,000$. With the heat sink attached, however, a value for $\bar{h}_{\text {enhanced }}$ of $2477 \mathrm{~W} / \mathrm{m}^{2} \mathrm{~K}$ was obtained with the same nozzle at the same Reynolds number. This represents an enhancement factor of 14.3. The enhancement factors for all the results obtained were in the range $8.3 \leqslant \varepsilon \leqslant 17.7$, the highest value being obtained with the $9 \times 1.59 \mathrm{~mm}$ array at $\mathrm{Re}=15,000$. It is emphasized that in the definition of $\bar{h}_{\text {enhanced }}$ in Eq. ( $\left.2 b\right)$ the resistance introduced by the interface material (measured to be $\approx 0.2^{\circ} \mathrm{C} / \mathrm{W}$ ) is excluded so that the bare and enhanced-surface heat transfer coefficients may be compared on the same basis.

It is also seen from Fig. 3(b) that the heat transfer rates in suction with the heat sink attached are similar for three nozzle configurations: the single $12.7 \mathrm{~mm}$ nozzle and the $9 \times 1.59$ and $4 \times 3.18 \mathrm{~mm}$ arrays. This may be attributed to the fact that the three nozzle plates have similar total volumetric flow rates for a given Reynolds number. A comparison between Figs. 3( $a$ ) and $3(b)$ shows that an increase in the number of nozzles of a given diameter has a much greater enhancing effect on heat transfer for the enhanced surface than for the bare surface. For $d=1.59 \mathrm{~mm}$, when the number of nozzles is increased from 1 to 9 , there is a

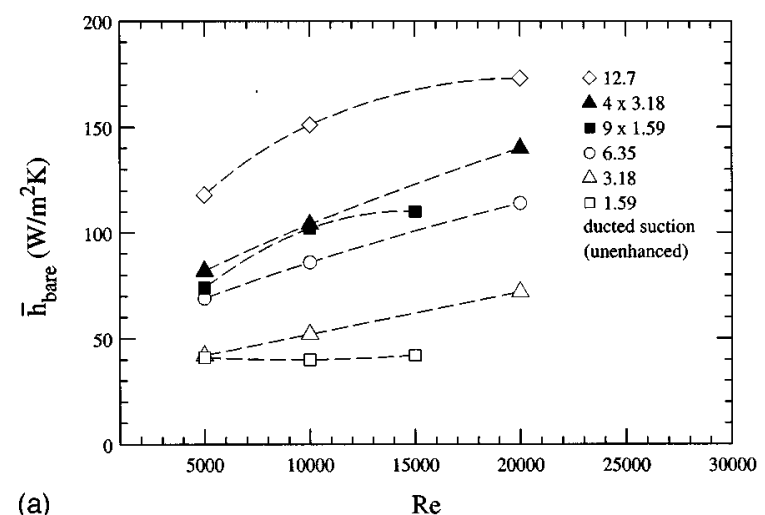

(a)

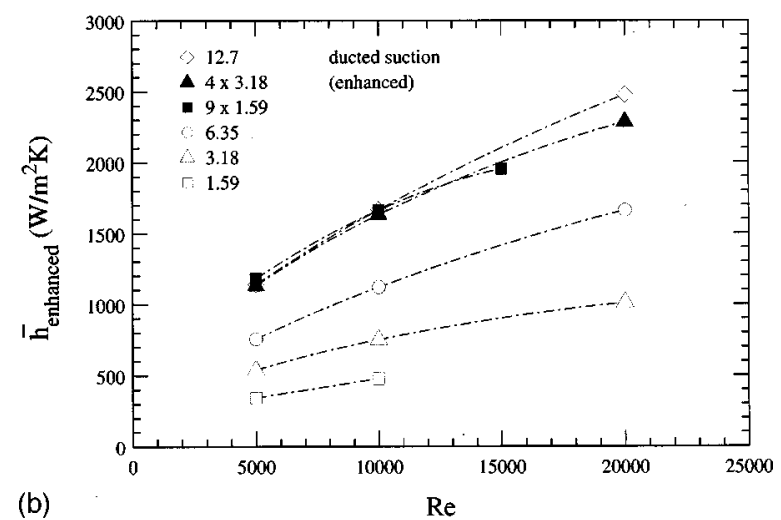

Fig. 3 (a) Bare-surface (Fig. 1(a), H=19.5 mm), and (b) enhanced-surface (Fig. $1(b), \mathrm{H}=21.9 \mathrm{~mm}$ ) heat transfer coefficients as a function of Reynolds number for all nozzle combinations

152 percent increase in $\bar{h}_{\text {bare }}$ (Fig. 3(a)) compared to a 245 percent increase in $\bar{h}_{\text {enhanced }}$ (Fig. 3(b)) for a given Reynolds number. With $d=3.18$, these increases are by 96 percent and 120 percent, respectively, when the number of nozzles is increased from 1 to 4 . It must be remembered that these increases (at fixed $\mathrm{Re}$ ) in heat transfer with the multiple nozzles are obtained at the expense of flow rates of air that are nine or four times higher than their single-nozzle counterparts. However, the pressure drop required is quite similar for single and multiple nozzles of the same diameter.

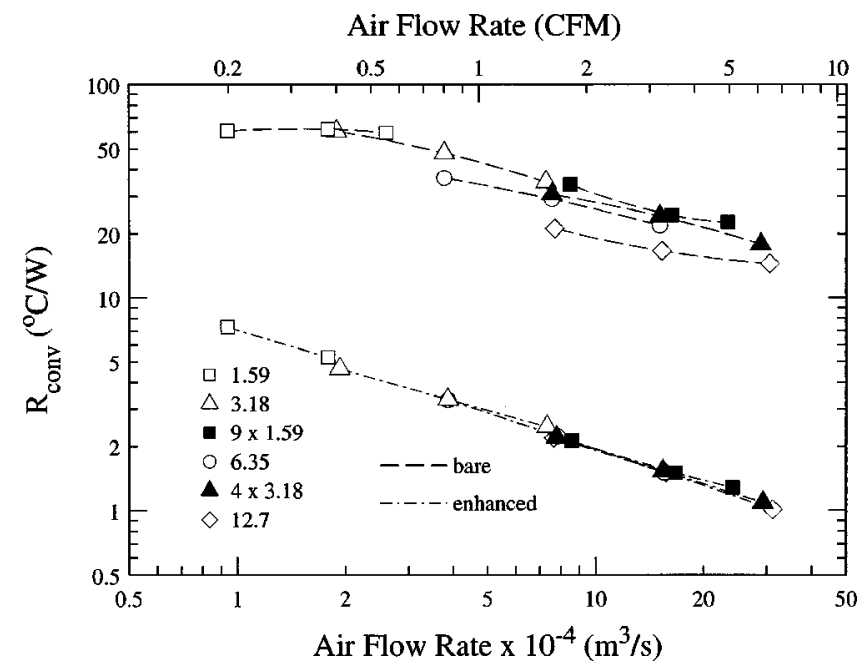

Fig. 4 Thermal resistance as a function of volumetric flow rate of air in suction for bare and enhanced-surface experiments 


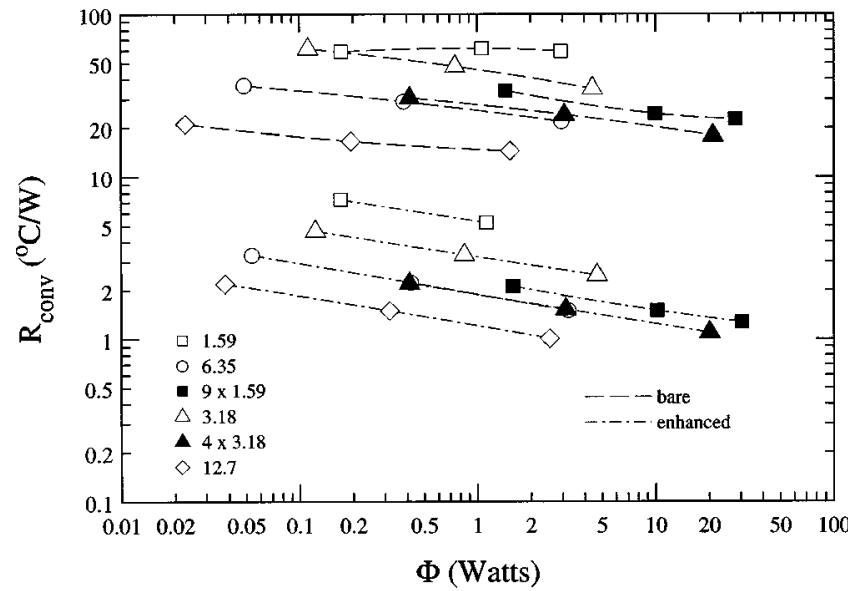

Fig. 5 Thermal resistance as a function of pumping power for suction

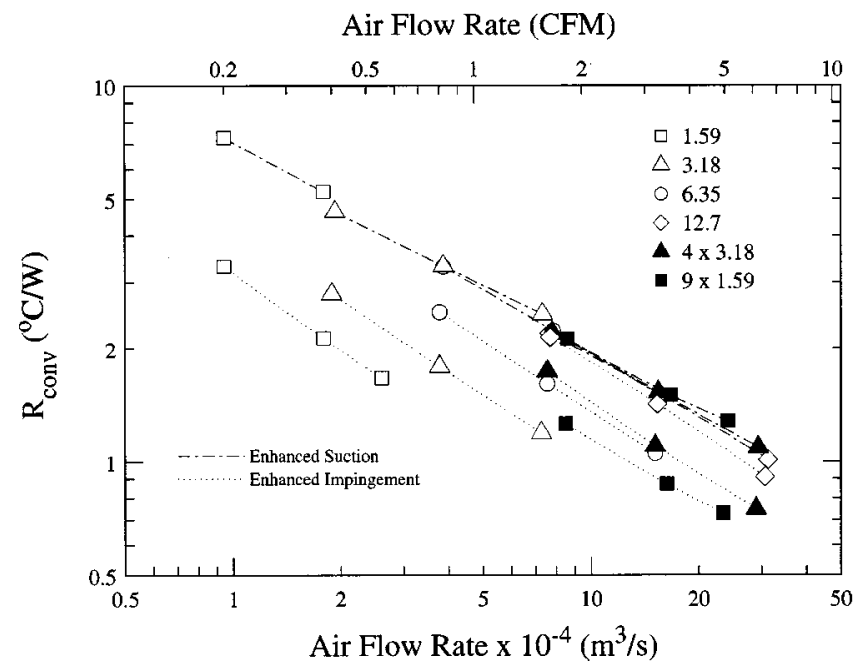

Fig. 6 Comparison of heat sink thermal resistance between suction and impingement (Figs. 1(b) and 1(c))

The heat sink thermal resistance ( $\left.R_{\text {conv }}\right)$ is an important parameter in practical applications, and is shown in Fig. 4 as a function of volumetric air flow rate for all the experiments, both with and without the heat sink in place. While the thermal resistance depends on nozzle configuration for the bare surface experiments, it shows a dependence only on the flow rate when the heat sink is present (and the curves for all nozzle plates collapse on to one line). The lowest value, $R_{\text {conv }}=1.01^{\circ} \mathrm{C} / \mathrm{W}$, was obtained with the $12.7 \mathrm{~mm}$ single nozzle at an air flow rate of $6.61 \mathrm{CFM}(\mathrm{Re}$ $=20,000)$.

Figure 5 shows the pumping power $(\Phi)$ required to meet a given thermal resistance requirement for each nozzle configuration. As expected, for a given pumping power and nozzle plate, Fig. 5 shows that considerably lower values for thermal resistance are obtained with suction flow from the heat sink than from a bare surface. For pumping power values of $0.4 \leqslant \Phi \leqslant 3.1 \mathrm{~W}$, two nozzle plates perform alike in suction $-d=6.35 \mathrm{~mm}$ and 4 $\times 3.18 \mathrm{~mm}$ - for both bare and enhanced surface experiments, since these nozzle configurations have the same open area. The $12.7 \mathrm{~mm}$ single nozzle is seen to be the best configuration in enhanced suction at any given pumping power.
As another useful comparison to evaluate the trade-offs involved in implementing a suction arrangement as opposed to conventional impingement, Fig. 6 shows thermal resistance values in suction and impingement with the heat sink present. From the results of the present study it is clear that air impingement outperforms suction in terms of thermal performance and leads to lower thermal resistances for a given flow rate. For example, at a flow rate of $0.37 \mathrm{CFM}$ the $1.59 \mathrm{~mm}$ single nozzle produced a thermal resistance of $2.13^{\circ} \mathrm{C} / \mathrm{W}$ for impingement and $4.98^{\circ} \mathrm{C} / \mathrm{W}$ for suction. However, suction is associated with other advantages such as reduced thermal-performance degradation due to heating of spent coolant. It is interesting to note that with impingement, results for the single $12.7 \mathrm{~mm}$ nozzle and the $4 \times 3.18$ and $9 \times 1.59 \mathrm{~mm}$ arrays are distinctly separated, suggesting a stronger dependence of heat transfer on nozzle exit velocity than that for suction. Copeland [2] evaluated the effects of changing the pin-fin parameters on heat transfer in liquid suction and impingement; however, the difference in performance of the two flow schemes could not be compared in that study. Results reported from experiments with boiling liquid flow comparing impingement and suction (McGillis and Carey [8]) showed similar performance between the two when compared at similar jet velocities; no surface enhancements were considered.

\section{Conclusions}

Experiments using air jet suction were conducted on a discrete heat source enhanced by a pin-fin heat sink with several single nozzles and multiple-nozzle arrays at different Reynolds numbers. Heat transfer was found to be a strong function of nozzle-to-target spacing for single and multiple nozzles in confined suction. Changes in nozzle-to-target spacing, especially for large nozzle diameters $(d=12.7$ and $6.35 \mathrm{~mm})$ also affected pressure drop. Larger enhancement factors $(8.3 \leqslant \varepsilon \leqslant 17.7)$ were obtained in suction upon the introduction of the heat sink when compared to impingement $(2.8 \leqslant \varepsilon \leqslant 9.7)$. However, on the basis of volumetric flow rate, air jet impingement yields lower values for heat sink thermal resistance than air suction.

\section{Acknowledgment}

Partial funding for this work provided by SGI/Cray Research of Chippewa Falls, Wisconsin, is gratefully acknowledged. LAB was supported through an Advanced Opportunity Program Fellowship from the University of Wisconsin-Milwaukee.

\section{References}

[1] Choi, S. B., and Kim, W. T., 1993, “Air jet impingement cooling of simulated multichip modules in the electronics," Adv. Electron. Packag., 4, pp. 679683.

[2] Copeland, D., 1995, "'Single-phase and boiling cooling of small pin-fin arrays by multiple slot nozzle suction and impingement," IEEE Trans. Compon., Packag., Manufact. Technol., 18, pp. 510-516.

[3] Bartilson, B. W., 1991, "Air jet impingement on a miniature pin-fin heat sink,'” ASME Paper No. 91-WA/EEP-41.

[4] Brignoni, L. A., and Garimella, S. V., 1999, "Experimental optimization of confined air jet impingement on a pin-fin heat sink," IEEE Trans. Compon. Packag. Technol., 22, pp. 399-404.

[5] El-Sheikh, H. A., and Garimella, S. V., 2000, "Heat Transfer in Multiple Air Jet Impingement Using Pin-Fin Heat Sinks,' IEEE Trans. Adv. Packag. 23, pp. $113-121$

[6] Schroeder, V. P., and Garimella, S. V., 1998, "Heat transfer from a discrete heat source in confined air jet impingement," Heat Transfer 1998, 5, pp. 451-456.

[7] Obot, N. T., and Trabold, T. A., 1987, “Impingement heat transfer within arrays of circular jets: Part 1-Effects of minimum, intermediate, and complete crossflow for small and large spacings," ASME J. Heat Transfer, 109, pp. $872-879$.

[8] McGillis, W. R., and Carey, V. P., 1990, “Immersion cooling of an array of heat dissipating elements-An assessment of different flow boiling methodologies," Cryogenic and Immersion Cooling of Optics and Electronic Equipment, ASME HTD-vol. 131, pp. 37-44. 